\title{
The 16-day wave in the Arctic and Antarctic mesosphere and lower thermosphere
}

\author{
K. A. Day and N. J. Mitchell \\ Bath, Bath, BA2 7AY, UK \\ Received: 10 September 2009 - Published in Atmos. Chem. Phys. Discuss.: 25 November 2009 \\ Revised: 25 January 2010 - Accepted: 30 January 2010 - Published: 11 February 2010
}

Centre for Space, Atmospheric and Oceanic Science, Department of Electronic and Electrical Engineering, The University of

Abstract. The 16-day planetary wave in the polar mesosphere and lower thermosphere has been investigated using meteor radars at Esrange $\left(68^{\circ} \mathrm{N}, 21^{\circ} \mathrm{E}\right)$ in the Arctic and Rothera $\left(68^{\circ} \mathrm{S}, 68^{\circ} \mathrm{W}\right)$ in the Antarctic. The measurements span the 10-year interval from October 1999 to July 2009 and the 5-year interval February 2005 to July 2009, respectively. The height range covered is about $80-100 \mathrm{~km}$. In both polar regions the wave is seen to occur in intermittent bursts, where wave amplitudes typically reach a maximum of about $15 \mathrm{~m} \mathrm{~s}^{-1}$, and never more than about $20 \mathrm{~m} \mathrm{~s}^{-1}$. Horizontal wind variance within a wave-period range of 12 to 20 days is used as a proxy for the activity of the 16-day wave. Wave activity is strong for 3 to 4 months in winter, where it is present across the entire height range observed and monthly wave variance reaches about $65 \mathrm{~m}^{2} \mathrm{~s}^{-2}$. Some weak and intermittent activity is observed throughout the other seasons including summer. However, there is a high degree of inter-annual variability and in some individual years wave activity is almost absent. The data are used to construct a representative climatology for the Arctic and Antarctic. The seasonal cycle of the 16-day wave is found to be very similar in both polar regions. The 16-day wave has slightly greater amplitudes in the zonal component of the winds than in the meridional. Mesospheric temperatures measured by the radars were used to further investigate the 16-day wave. The temperatures reveal a clear signature of the 16-day wave. Temperature amplitudes are generally only a few Kelvin but occasional bursts of up to $10 \mathrm{~K}$ have been observed. Observations of the wave in summer are sometimes consistent with the suggestion of ducting from the winter hemisphere.

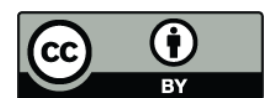

Correspondence to: K. A. Day (k.a.day@bath.ac.uk)

\section{Introduction}

Planetary waves are important agents in the coupling between the layers of the atmosphere. They act to move energy, momentum and chemical species both horizontally and vertically in the atmosphere. Planetary waves are known to propagate from sources in the troposphere and stratosphere into the mesosphere and lower thermosphere (MLT) and also to be generated in situ in the MLT (e.g., Charney and Drazin, 1961; Dickinson, 1968; Salby, 1981a,b; Forbes et al., 1995). Planetary waves can reach amplitudes of several tens of $\mathrm{m} \mathrm{s}^{-1}$ in the MLT. The waves are known to interact with and modulate the amplitudes of atmospheric tides (e.g., Teitelbaum and Vial, 1991; Beard et al., 1997). They also modulate the gravity-wave field of the middle atmosphere (e.g., Forbes et al., 1991; Miyahara and Forbes, 1991a; Thayaparan et al., 1995; Nakamura et al., 1997; Manson et al., 1998, 2003). Planetary waves with a period of 16 days have been reported in observations of wind, temperature and geopotential height in the MLT region (e.g., Forbes et al., 1995; Espy and Witt, 1996; Espy et al., 1997; Mitchell et al., 1999; Luo et al., 2000, 2002a,b; Manson et al., 2003; Jiang et al., 2005; Lima et al., 2006). The temperature perturbations associated with planetary waves are believed to modulate the occurrence of Polar Mesospheric Clouds (e.g., Espy and Witt, 1996; Merkel et al., 2003, 2008). Modelling studies have also investigated the 16-day wave (e.g., Forbes et al., 1995; Miyoshi, 1999; Luo et al., 2002b).

The wave has been reported to have amplitudes of up to $\sim 20 \mathrm{~m} \mathrm{~s}^{-1}$ in the winter-time MLT and up to $\sim 7 \mathrm{~m} \mathrm{~s}^{-1}$ in the summer-time MLT. The vertical wavelength has generally been reported to have values between $\sim 30$ to $60 \mathrm{~km}$ (e.g., Luo et al., 2000, 2002a,b). The 16-day wave has been identified as the manifestation of the gravest symmetrical wavenumber 1 westward travelling, $s=1$, Rossby mode and

Published by Copernicus Publications on behalf of the European Geosciences Union. 
suggested on theoretical grounds to occur with periods between 11.1-20.0 days (e.g., Salby, 1981b).

A number of studies have investigated the 16-day wave at mid- and low-latitudes in the MLT region. These studies have revealed that the wave has a clear seasonal behaviour in the MLT and displays wave periods of between about 12 to 20 day, as predicted by Salby (1981b). Forbes et al. (1995) analysed 2 months of wind data, from a meteor-radar over Obninsk, $\left(54^{\circ} \mathrm{N}\right)$ and from a medium-frequency (MF) radar over Saskatoon $\left(52^{\circ} \mathrm{N}\right)$ to observe the 16-day wave in the MLT at a time when there was a large oscillation in the troposphere and stratosphere. Mitchell et al. (1999) used 5 years of meteor-radar wind data and reported that the 16-day wave maximised in winter and was also present in late summer over the UK at $53^{\circ} \mathrm{N}$. The comprehensive studies of Luo et al. (2000, 2002a,b) used MF-radars, HRDI/UARS and The Global Scale Wave Model. They used wind data to observe the 16-day wave and reported largest wave amplitudes in winter and smaller amplitudes in summer. Jiang et al. (2005) used meteor-radar wind data from over Wuhan $\left(31^{\circ} \mathrm{N}\right)$ and MF-radar data from over Adelaide $\left(35^{\circ} \mathrm{S}\right)$ to study the 16 day wave in 2002 and 2003. The wave was observed in all seasons over at least one of the sites. In general, the midlatitude studies suggest that wave activity is strongest in winter with a secondary maximum occurring around the summer mesopause.

At lower latitudes Lima et al. (2006) observed the MLT region for five years with a meteor-radar at Cachoeira Paulista $\left(23^{\circ} \mathrm{S}\right)$. They concluded that there was no clear seasonal behaviour and that the strongest wave activity was observed in autumn-winter for some years and spring-summer for others.

In contrast to the situation at mid-latitudes, there have been only a limited number of studies of the 16-day wave in the polar MLT. Williams and Avery (1992) used a mesospherestratosphere-troposphere (MST) radar to observe winds over Poker Flat $\left(65^{\circ} \mathrm{N}\right)$ and reported significant wave activity in summer and winter. Espy et al. (1997) used optical measurements of $\mathrm{OH}$-layer temperatures over Stockholm $\left(60^{\circ} \mathrm{N}\right)$ in the summers of 1992 to 1995 to investigate the 16-day wave. They reported a temperature oscillation corresponding to the 16-day wave. Luo et al. (2002b) used an MF-radar and reported observations of winds over Troms $\varnothing\left(70^{\circ} \mathrm{N}\right)$ during 1993 to 1994 . They also reported stronger wave activity in the winter, but some summer-time wave activity was also evident.

Miyoshi (1999) reported numerical simulations in which the 16-day wave maximised in winter and summer, with the winter amplitudes being greater. It was suggested that the 16-day wave may be mainly excited by heating due to the moist convection in the troposphere.

One of the most interesting things about the 16-day wave is that a number of explanations have been proposed for the wave activity observed in summer. The key point here is that the summer-time wave activity in the MLT cannot have propagated to those heights from the summer tropo- sphere/stratosphere. This is because the 16-day wave has a low zonal phase speed and so wave propagation is prohibited through the strong westward winds of the summer-time middle atmosphere (Charney and Drazin, 1961).

A mechanism that could account for in situ excitation of the wave has been proposed by Williams and Avery (1992). In this mechanism, gravity waves rising from the lower atmosphere are filtered by a 16-day wave in the troposphere/stratosphere. This imposes a 16-day modulation on the gravity-wave field in the MLT. As these gravity waves dissipate and transfer their momentum into the mean flow of the MLT this then excites a 16-day wave in situ. Smith (2003) demonstrated in a modelling study that this mechanism can produce significant planetary-wave amplitudes in the MLT, at least for stationary planetary waves.

An alternative explanation proposed by Miyahara et al. (1991b) is that the 16-day wave of the winter hemisphere propagates across the equator into the summer-time MLT at heights above the strong westward flow of the summer-time middle atmosphere. This suggestion received further support from the modelling study of Forbes et al. (1995). However, these authors also noted that this ducting may be impeded by gravity-wave stresses in the mesosphere. Experimental results which suggest such ducting takes place have been reported by Espy et al. (1997) and Hibbins et al. (2009). These authors report a correlation between long-period planetary wave activity in the summer polar mesosphere and the phase of the equatorial Quasi-Biennual Oscillation (QBO), such that largest amplitudes occur during eastward phases of the QBO. These suggest that the waves observed in the polar regions have travelled there across the equator from the winter hemisphere, i.e., have been ducted.

Here we present observations of winds and temperatures in the MLT made using two meteor radars, one at Esrange in the Arctic and one at Rothera in the Antarctic. These radars are located at conjugate geographical latitudes. Comparatively long data sets are available from the sites (10 and 5 years, for Esrange and Rothera, respectively). The data from these radars are used to characterize the inter-annual variability of the 16-day wave in the polar MLT and to construct simple representative climatologies of the 16-day wave in the Arctic and Antarctic MLT.

\section{Data analysis}

Two all-sky meteor radars were used in this study. The radars are SKiYMET VHF systems that operate with radiated power being largely independent of azimuth. The radio frequency that the radars operate at is $32.5 \mathrm{MHz}$, the pulse repetition frequency is $2144 \mathrm{~Hz}$, the duty cycle is $15 \%$ and the peak power is $6 \mathrm{~kW}$. One radar is located at Esrange in Arctic Sweden $\left(68^{\circ} \mathrm{N}, 21^{\circ} \mathrm{E}\right)$. It was deployed in August 1999 and has produced largely-uninterrupted measurements since October of that year. The other is located at Rothera in the 
Antarctic $\left(68^{\circ} \mathrm{S}, 68^{\circ} \mathrm{W}\right)$. It was deployed in February 2005 and again has produced largely-uninterrupted measurements since deployed. This gives a near-continuous data set of approximately ten years for Esrange and five years for Rothera.

Horizontal winds are measured by both radars at heights of $\sim 80-100 \mathrm{~km}$. Six independent non-overlapping height gates are used with representative height and time resolutions of either 3 or $5 \mathrm{~km}$ and $1 \mathrm{~h}$, respectively. The vertical distribution of meteor echoes is strongly peaked at a height of $\sim 90 \mathrm{~km}$. The height gates used from 80 to $100 \mathrm{~km}$ have depths of 5, $3,3,3,3,5 \mathrm{~km}$ to ensure there are sufficient meteors in the uppermost and lowermost height gates. The meteor-countweighted centres of the height-gates are at $80.8,84.7,87.5$, $90.4,93.3$ and $97.1 \mathrm{~km}$. The horizontal winds are calculated for each height gate in time steps of $1 \mathrm{~h}$ and resolved into zonal and meridional wind components. A more full description of the radars and data analysis can be found in Hocking et al. (2001) and Mitchell et al. (2002). These time series of the hourly winds form the basis of the wind data analysis presented here.

To complement the wind data, temperatures can also be measured by both of the radars. The temperature data is a daily value, representative of the whole height range available, thus supplying one daily temperature for the meteor region. The temperature data used here for Esrange covers the interval from August 2002 to July 2009 and for Rothera from February 2005 to July 2009. A full description of the temperature data analysis can be found in Hocking (1999); Hocking et al. (2001, 2004).

As described in Sect. 1, the 16-day planetary wave has been observed to occur with a wide range of periods between $\sim 12$ to 20 days. Here, we will consider all planetary wave activity within the period range 12 to 20 day to be attributable to the "16-day wave". This range of periods has also been used in the studies of e.g., Forbes et al. (1995); Luo et al. (2002a); Jiang et al. (2005); Lima et al. (2006), and is used here so that our results will be directly comparable with these other studies.

\section{Results}

To investigate the planetary-wave field over Esrange and Rothera, the time series of winds recorded over each site were analyzed using a wavelet technique. The wavelet analysis uses a Morlet wavelet of non-dimensional wavenumber 6. This wavelet and wavenumber were chosen because they have approximately similar form to the bursts of planetary wave activity often reported in the MLT (e.g., Kumar and Foufoula-Georgiou, 1997; Pancheva and Mukhtarov, 2000; Lastovicka et al., 2006).

An example of this analysis is shown in Fig. 1. The figure presents the results of the wavelet analysis for zonal winds recorded at a height of $\sim 85 \mathrm{~km}$ over Esrange and Rothera in the time interval 2005 to 2009 . These years are presented
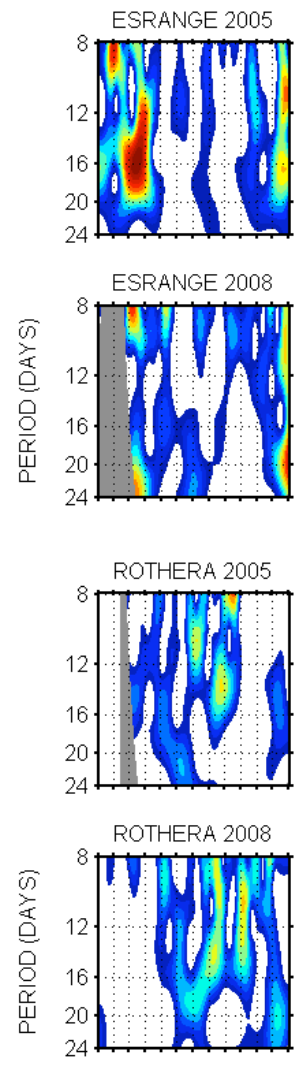
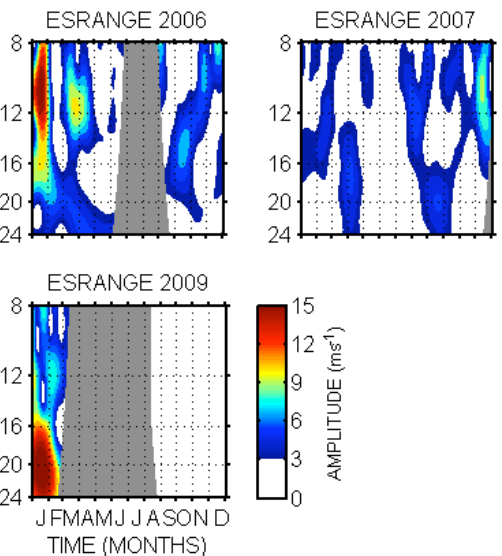

ROTHERA 200
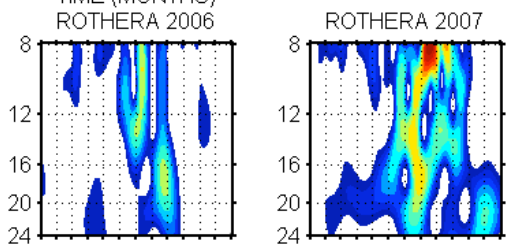

ROTHERA. 2009

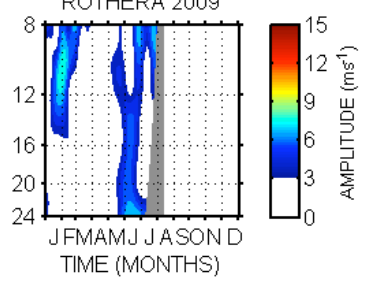

Fig. 1. A wavelet analysis of (a) hourly zonal winds over Esrange at a height of $84.7 \mathrm{~km}$ during the interval January to December 2005 to 2009 and (b) hourly zonal winds over Rothera at a height of $84.7 \mathrm{~km}$ during the interval January to December 2005 to 2009. Amplitudes smaller than $3 \mathrm{~m} \mathrm{~s}^{-1}$ are not plotted.

because they are the ones in which simultaneous data exists for Esrange and Rothera. Results are only plotted for amplitudes greater than $3 \mathrm{~m} \mathrm{~s}^{-1}$ to highlight episodes of strong wave activity.

From the figures it can be seen that the planetary-wave activity is intermittent and occurs in bursts lasting approximately 1-2 months. Further, the wave period varies from burst to burst and is only approximately 16 days. A significant number of wave bursts are observed across the whole period range 12 to 20 days. For example, a burst of strong wave activity is evident in March 2005 over Esrange with a period of near 16 days. However, over Rothera in July 2005 the period of the burst of wave activity is nearer 13 days. Considering only the 16-day wave, it can be seen that wave amplitudes reached as large as $\sim 15 \mathrm{~m} \mathrm{~s}^{-1}$ over Esrange and $\sim 10 \mathrm{~m} \mathrm{~s}^{-1}$ over Rothera. Other bursts of wave activity are evident that occur at wave periods outside of the 12 to 20 day range. For example, strong wave activity with a period near 9 days is evident over Esrange in January 2005 and over Rothera August 2007. 
BANDPASSED ZONAL WINDS OVER ESRANGE

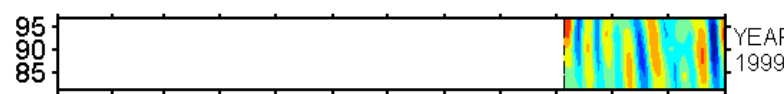

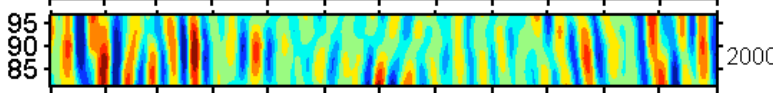

95
85

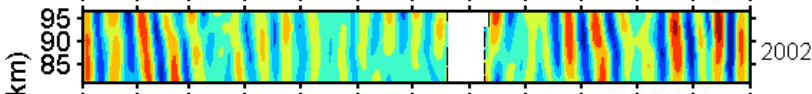

95

동

포

95

85.
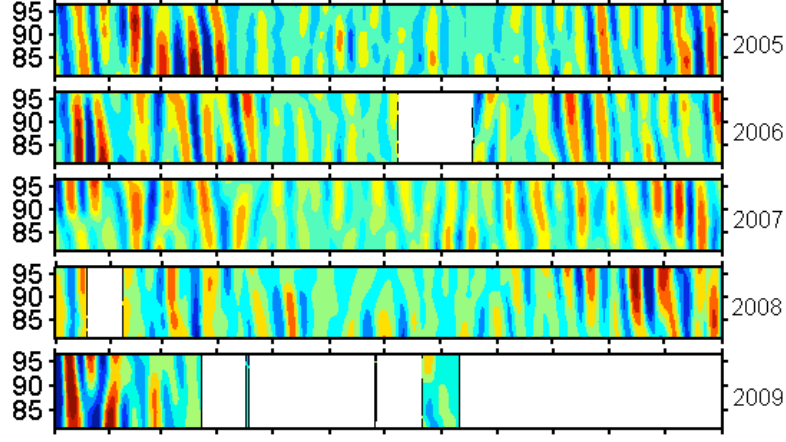

$\begin{array}{llllllllllll}J & F & M & A & M & J & J & A & S & O & N & D\end{array}$ TIME (MONTHS)

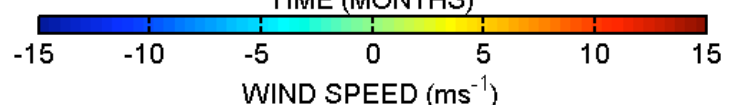

BANDPASSED ZONAL WINDS OVER ROTHERA

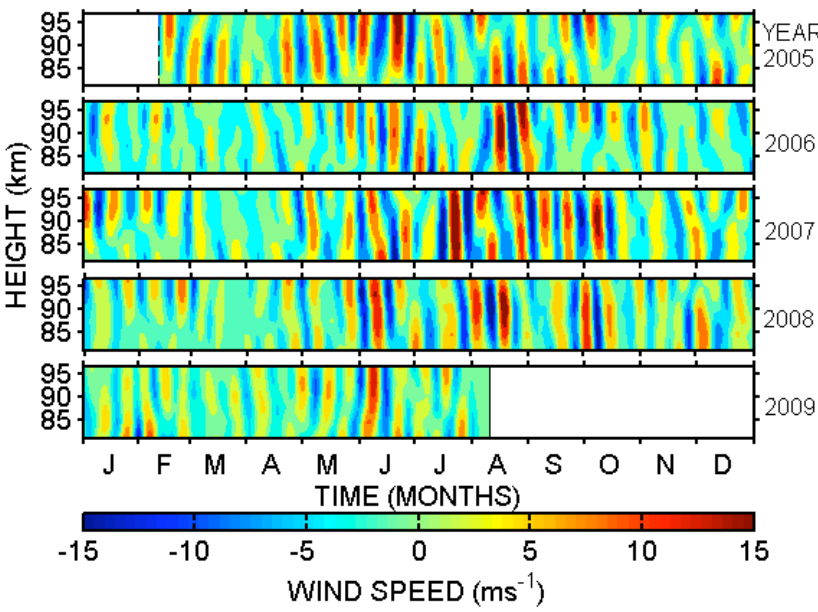

Fig. 2. Time-height contours of (a) the hourly zonal winds bandpassed between 12 and 20 days over Esrange and (b) the hourly zonal winds band-passed between 12 and 20 days over Rothera.

To investigate these 16-day waves further, a band-pass analysis of the horizontal winds in each height gate was performed. A second-order Butterworth band-pass filter was used that had period limits of 12 to 20 days (the filter used is the standard Butterworth found within MatLab). These period limits were chosen to make the analysis as similar as possible to that of some previous studies e.g., Espy et al. (1997); Mitchell et al. (1999); Luo et al. (2002b); Jiang et al. (2005). From the wavelet analysis in Fig. 1 it can be seen that wave activity is significant within this period range and the theoretical work mentioned above suggests that this is due to a global-scale wave number 1 planetary wave. Hereafter we will refer to oscillations within this period range and as the "16-day wave".

The vertical structure of the wave was then investigated using the six independent height gates available from each of the radars. The time-height contours of the band-passed zonal winds recorded over Esrange and Rothera are presented in Fig. 2a and b, respectively (the meridional winds, not shown, reveal a generally similar behavior). The data is for all years of data available, i.e. for Esrange, 1999 to 2009 and for Rothera, 2005 to 2009. Wave activity is evident in all years observed. Wave activity is generally stronger in winter than summer and is present in all winters observed. The wave is present in most summers observed, but is generally significantly weaker than in winter. Only in one year, 2005, does wave activity appear to fall below amplitudes of $\sim 3 \mathrm{~m} \mathrm{~s}^{-1}$ in summer. The bandpassed winds reveal a strongly phase coherent wave structure across the height range observed. Clear phase fronts are evident in all seasons, although the pattern begins to break up when the wave reaches small amplitudes in some summer months. This phase coherency across the six independent height gates provides strong evidence that the data are revealing the presence of a 16-day planetary wave.

Considering the figure in more detail, it can been seen that the winter-time wave is present through all the heights observed. The winter-time enhancement in amplitude lasts for several months and extends into the equinoxes, for instance the months of October to March over Esrange and May to October over Rothera. Wave amplitudes regularly reach $\sim 15 \mathrm{~m} \mathrm{~s}^{-1}$ for intervals of several months. For example, over Esrange this amplitude is reached in most years from October to March. A similar behaviour is observed over Rothera with strong wave activity evident from May to October. However, there is also significant inter-annual variability. For example, over Esrange in December 2001 the amplitude is mostly below $\sim 5 \mathrm{~m} \mathrm{~s}^{-1}$, whereas in December 2003 it is mostly above $15 \mathrm{~m} \mathrm{~s}^{-1}$. Similarly, over Rothera in July 2006 the amplitudes are generally less than $5 \mathrm{~m} \mathrm{~s}^{-1}$ compared with July 2007 where they reach $15 \mathrm{~m} \mathrm{~s}^{-1}$.

In contrast to the winter, wave amplitudes are generally smaller in summer. However, there are still some episodes of strong, but short-lived activity in the summer where wave amplitudes reach between 5 and $10 \mathrm{~m} \mathrm{~s}^{-1}$ on several occasions. For example, over Esrange in June and July at heights at below $90 \mathrm{~km}$ in 2000 and for the same months at heights above $90 \mathrm{~km}$ in 2004. Summer-time wave activity is even stronger over Rothera. For example, wave amplitude exceed $10 \mathrm{~m} \mathrm{~s}^{-1}$ in January and February in 2007. 
Over Esrange there are six years where we have a continuous three months of data for observing the 16-day summertime wave. In this there are five bursts where amplitudes reach greater than $5 \mathrm{~m} \mathrm{~s}^{-1}$. Over Rothera there are four bursts reaching amplitudes greater than $5 \mathrm{~m} \mathrm{~s}^{-1}$.

Examination of the phase fronts of the wave reveals that there is phase slope with height. Good examples of this include November and December over Esrange in 2003 and August to October over Rothera in 2007. This suggests that the vertical wavelength, even though still long, is not as long as other planetary waves. A least squares fit to the data for winter conditions suggests a vertical wavelength of $\sim 70 \mathrm{~km}$.

The seasonal and long-term variability suggested above can be investigated further using horizontal wind variance as a proxy for wave activity. In this analysis the band-passed winds in each height gate for each month are used to calculate a variance value for the meridional and zonal components of the winds. By examining these variances as a function of height and time the seasonal and inter-annual behavior of the 16-day wave can be investigated. A similar analysis has been used in the the study of the 2-day and 5-day planetary waves (Tunbridge and Mitchell, 2009; Day and Mitchell, 2010). Note that for a constant-amplitude oscillation, amplitude is equal to the square root of twice the variance. For example, a variance of $10 \mathrm{~m}^{2} \mathrm{~s}^{-2}$ corresponds to a wave amplitude of $4.5 \mathrm{~m} \mathrm{~s}^{-1}$, a variance of $50 \mathrm{~m}^{2} \mathrm{~s}^{-2}$ corresponds to a wave amplitude of $10 \mathrm{~m} \mathrm{~s}^{-1}$ and a variance of $100 \mathrm{~m}^{2} \mathrm{~s}^{-2}$ corresponds to a wave amplitude of $14.1 \mathrm{~m} \mathrm{~s}^{-1}$ etc.

Time-height contours of meridional and zonal monthly variances for all the years available over Esrange are presented in Fig. 3. The monthly-mean zonal winds for each year have been plotted over the top of the figure for that specific year to enable a comparison of the background winds and the level of 16-day wave activity.

Figure 3 shows a clear seasonal cycle in Arctic wave activity on top of which is superposed significant inter-annual variability. Wave activity is strongest in winter. For example, zonal variances in February and March of 2005 show a strong 16-day wave at $\sim 85 \mathrm{~km}$ where variances reach values in excess of $\sim 100 \mathrm{~m}^{2} \mathrm{~s}^{-2}$. In contrast, during February and March of 2007, wave variances at the same height reached only $\sim 30 \mathrm{~m}^{2} \mathrm{~s}^{-2}$.

When considering the strong winter-time wave it can be seen that the zonal component is greater than the meridional for most winters (the average difference is approximately a factor of 1.2). Consideration of the figure shows that the wave has generally largest variances in the winter and equinoxes.

In the summer the wave is present but has significantly smaller variances and is sometimes completely absent. For example, in the summer of 2003, zonal wave variance reaches values of $\sim 35 \mathrm{~m}^{2} \mathrm{~s}^{-2}$ at the upper heights in June and July. Similarly, the summers of 2000, 2003, 2005 and 2007 all show wave activity with variances in the range of 15 to $40 \mathrm{~m}^{2} \mathrm{~s}^{-2}$. Careful inspection of the bandpass data (Fig. 2)
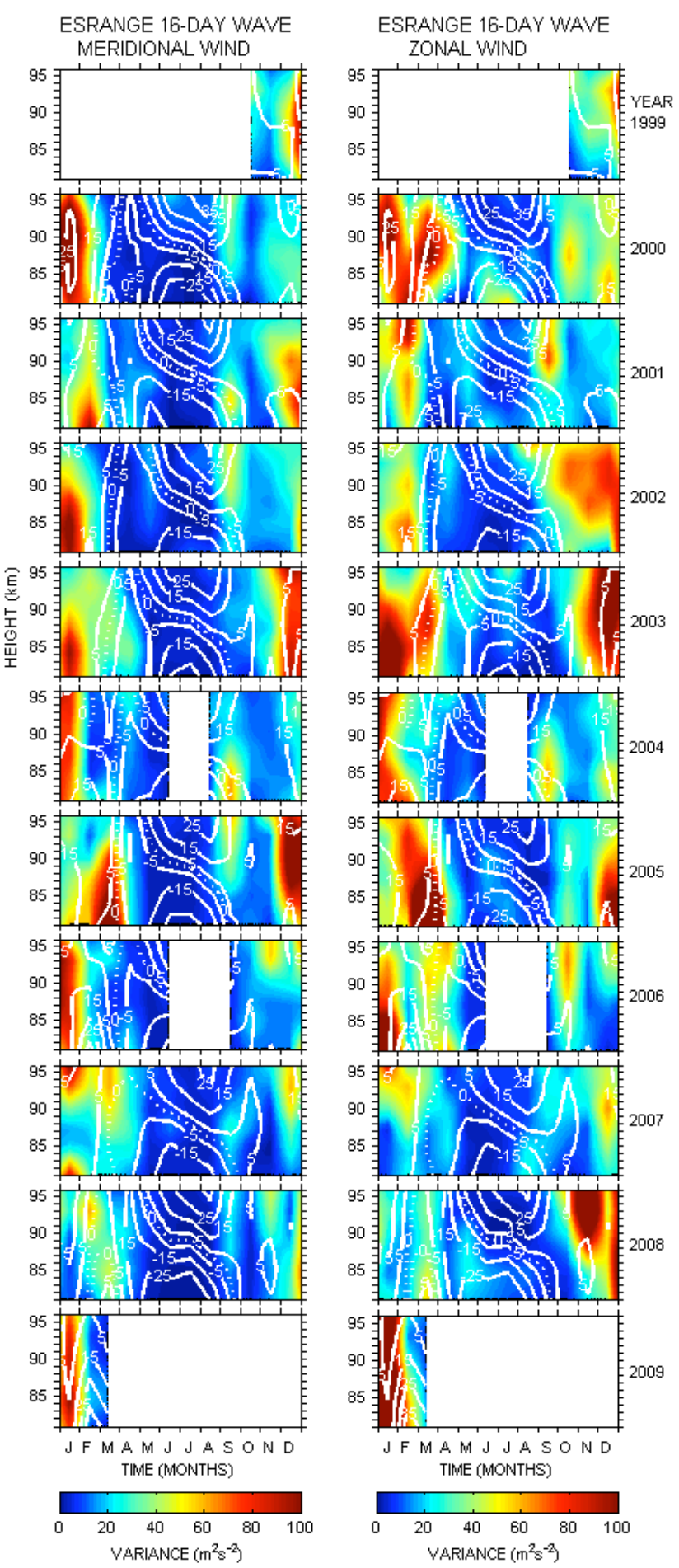

Fig. 3. Time-height contours (filled color contours) of the monthly variance of winds band-passed between 12 and 20 days over Esrange in the Arctic for both meridional and zonal components, for 1999 to 2009. Also plotted are the monthly-mean zonal winds. The zero-wind line is indicated by the heavy dashed line. 


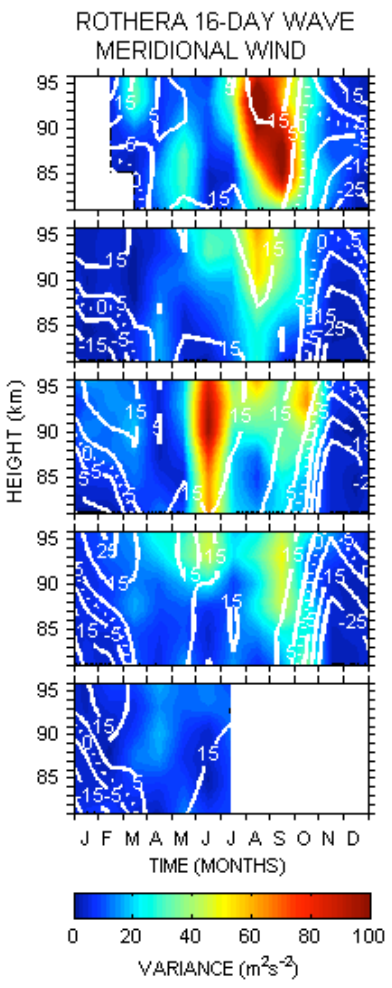

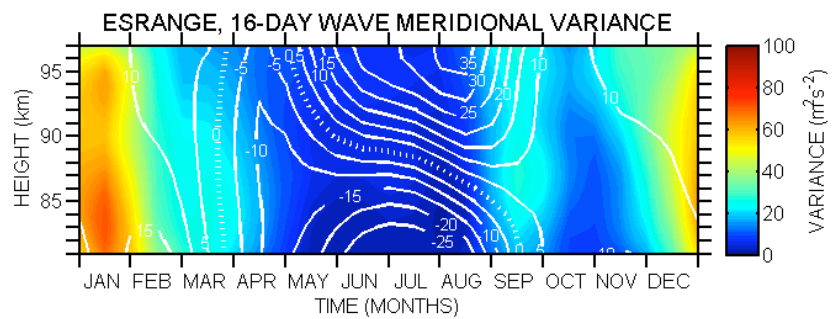

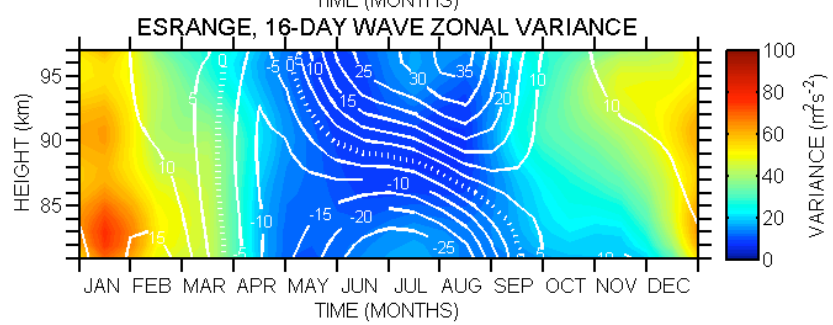

Fig. 5. A composite-year analysis of 16-day wave activity over Esrange in the Arctic for the years 1999 to 2009 (filled color contours) for the meridional component, top panel, and zonal component, bottom panel. Also shown are the composite-year monthly-mean zonal winds (contour lines). The zero-wind line is indicated by the heavy dashed contour line.

The observations of Figs. 3 and 4, however, reveal significant wave activity in winds more westerly than this value. Similar behaviour has been reported by, e.g., Luo et al. (2002b) and probably reflects the fact that the Charney-Drazin theorem is an approximation.

In order to investigate the seasonal variability of the 16day wave in more detail, a composite-year ("superposed epoch") analysis was applied in which data from all years was used. A simple arithmetic mean of the monthly variances was used. The results of this analysis are shown in Figs. 5 and 6.

Figure 5 presents a composite-year analysis of the monthly meridional and zonal wave activity calculated using all the years of data available over Esrange, October that is 1999 to July 2009. The monthly-mean zonal winds from the same period of time are plotted on the figure as contour lines. It can be seen that the strongest wave activity is in winter and maximizes in January where variances reach $\sim 70 \mathrm{~m}^{2} \mathrm{~s}^{-2}$. Wave activity is present at all heights observed. Wave activity is evident into the equinoxes and is generally very weak in summer.

Figure 6 presents a similar analysis for Rothera. It can be seen that the strongest wave activity is again in winter and maximizes in August where variances reach $\sim 65 \mathrm{~m}^{2} \mathrm{~s}^{-2}$. Note that this is approximately one month later than in the Arctic, but this is based on only five complete winters of observations and so may not be significant. Again, wave activity extends into the equinoxes and is weakest in summer.

However, note that this analysis will tend to mask the short-lived occasional bursts of activity present in summer 

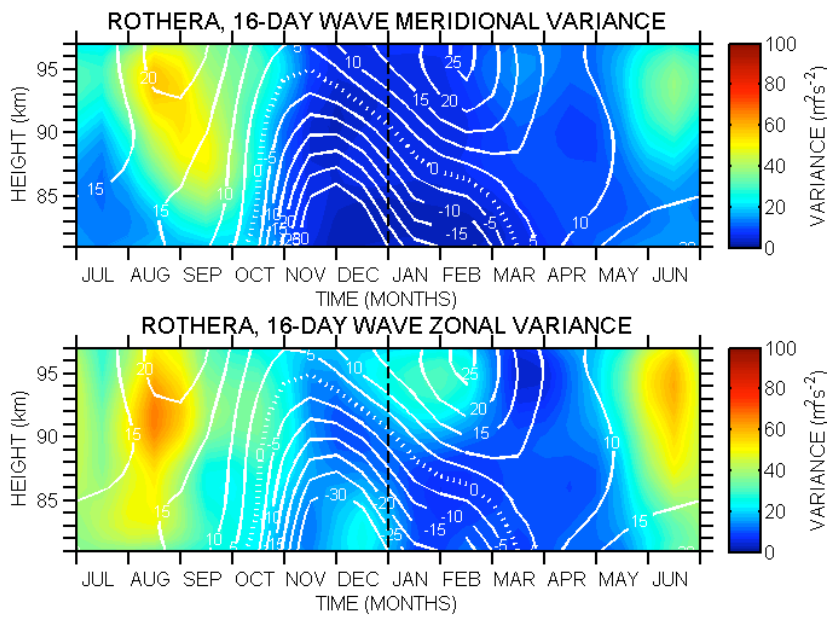

Fig. 6. A composite-year analysis of 16-day wave activity over Rothera in the Arctic for the years 2005 to 2009 (filled color contours) for the meridional component, top panel, and zonal component, bottom panel. Also shown are the composite-year monthlymean zonal winds (contour lines). The zero-wind line is indicated by the heavy dashed contour line.

as seen in Fig. 2a and b. This is because the bursts are sometimes of less than one-month duration and do not occur every year and so are smoothed out in the multiple-year composite analysis of Figs. 5 and 6 . In some years the high level of inter-annual variability evident in Figs. 3 and 4 means the strongest wave activity occurs one or two months either side of the maxima evident in Figs. 5 and 6.

The radars also produce a daily estimate of meteor-region temperature. This was used in a further investigation of the 16-day wave. The temperature time series from each radar was subject to a band-pass analysis with the same bandpass filter and limits as those used for the winds of Fig. 2 to Fig. 6. Temperature data are available from August 2002 over Esrange and February 2005 over Rothera.

Figure 7 presents the bandpassed daily temperatures and zonal winds over Esrange and Rothera, respectively. The heights chosen for the wind time-series are $\sim 85 \mathrm{~km}$ and $\sim 93 \mathrm{~km}$, respectively. These height gates were chosen because they are the corresponding heights at which the largest wind variances occur in Figs. 5 and 6. The figure allows comparison of each year's temperature and wind perturbations. From the figure it can be seen that there are bursts of wave activity in the temperatures. Generally these bursts coincide with bursts of wave activity in the winds. A number of the strongest bursts of coincident temperature and wind fluctuations are indicated by a $*$ on the figures. These bursts are selected as those event where the wind amplitude exceeds $5 \mathrm{~m} \mathrm{~s}^{-1}$ for more than one cycle of the wave.

The coincidence of the bursts in both wind and temperature provide strong support for the suggestion that the fluctu-
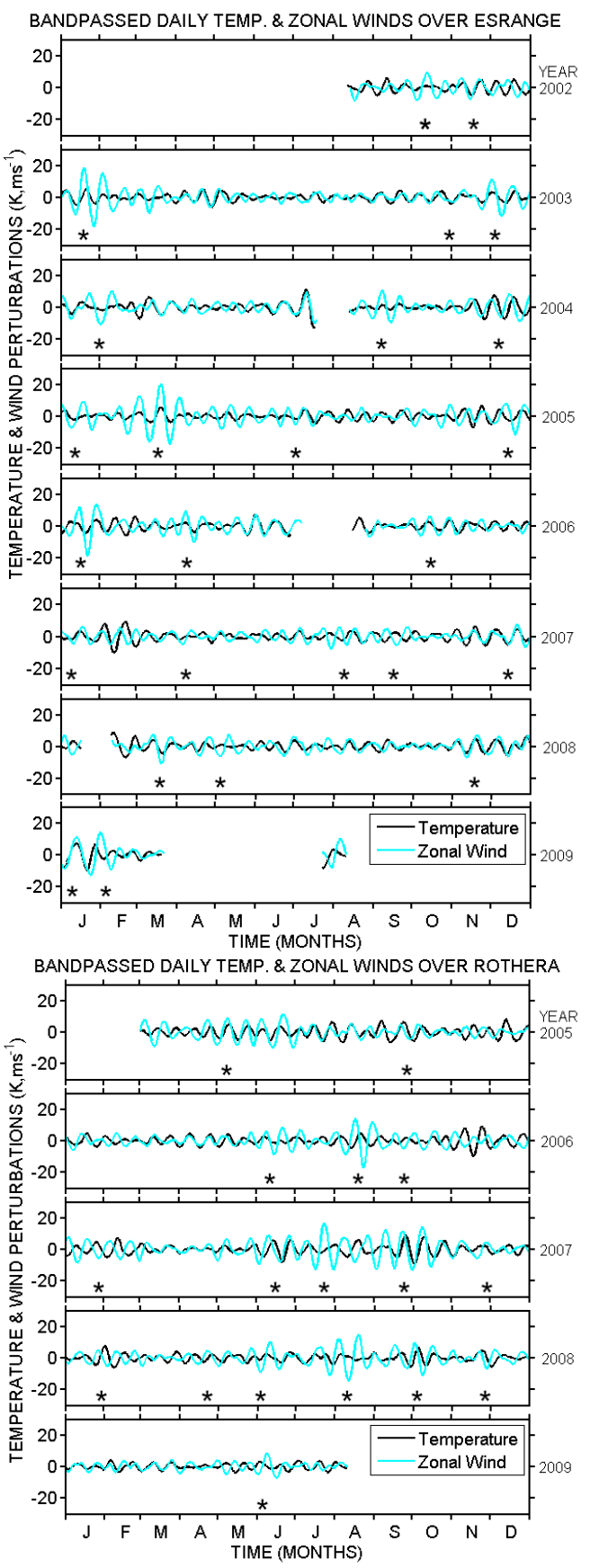

Fig. 7. Band-passed mean daily zonal winds and daily temperatures over (a) Esrange, at $\sim 85 \mathrm{~km}$ and (b) Rothera, at $\sim 93 \mathrm{~km}$, for the years 2002 to 2009 . Band-pass limits are for the wave periods of 12 to 20 days. Coincident bursts of wave activity in temperature and winds are marked by $\mathrm{a} *$.

ations in the temperature time series are caused by the 16-day planetary wave.

From the figure it can be seen that there were 25 such bursts observed over Esrange and 17 observed over Rothera. 


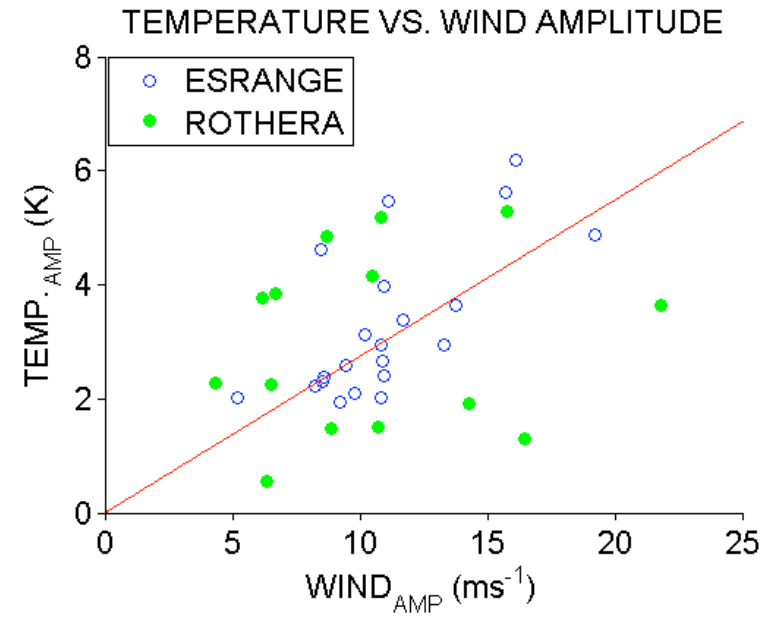

Fig. 8. A least-square fit of temperature versus wind amplitude for bursts of activity over Esrange and Rothera that are greater than $5 \mathrm{~m} \mathrm{~s}^{-1}$, last for longer than 1 cycle and passing the Student T-test $90 \%$ confidence level.

Generally, larger bursts of activity in zonal winds correspond to larger bursts of activity in temperature perturbations. For example, in June 2003 over Esrange the $\sim 15 \mathrm{~m} \mathrm{~s}^{-1}$ amplitude winds are accompanied by $\sim 5 \mathrm{~K}$ amplitude temperature perturbations. A similar event can be seen over Rothera in September-October 2007. The wind perturbation and temperature perturbations are $\sim 10 \mathrm{~m} \mathrm{~s}^{-1}$ and $\sim 8 \mathrm{~K}$, respectively. It can be seen that when the wind and temperature perturbations are at their largest values they appear to be generally in phase. This is evident in most events marked by a* in Fig. 7 .

The bursts of wave activity show that there is a relationship between wind and temperature perturbations. Generally, greater wind perturbations correspond to greater temperature perturbations. The temperature perturbations range from $1 \mathrm{~K}$ to more than $6 \mathrm{~K}$. To quantify the relationship between them, a least squares fit of the wind and temperature amplitudes for the above bursts of activity was carried out. The burst are also subjected to the criteria of the Student T-test for them to be statistically related at a $90 \%$ confidence level. Figure 8, presents the wind and temperature amplitudes determined for the 35 burst of wave activity that satisfied this criterion over Esrange and Rothera. A least-squares straight-line fit to these data suggests that temperature and wind perturbations, $T^{\prime}$ and $u^{\prime}$, are related by $T^{\prime}=0.27 u^{\prime}$. Note that the fit was forced through zero.

The seasonal behaviour of the 16-day wave can also be investigated using the temperature data. A temperature variance can be used as a proxy for wave activity in much the same way as the analysis of the wind data, although there is no height resolution for the temperature data and thus it represents an average across the meteor region.

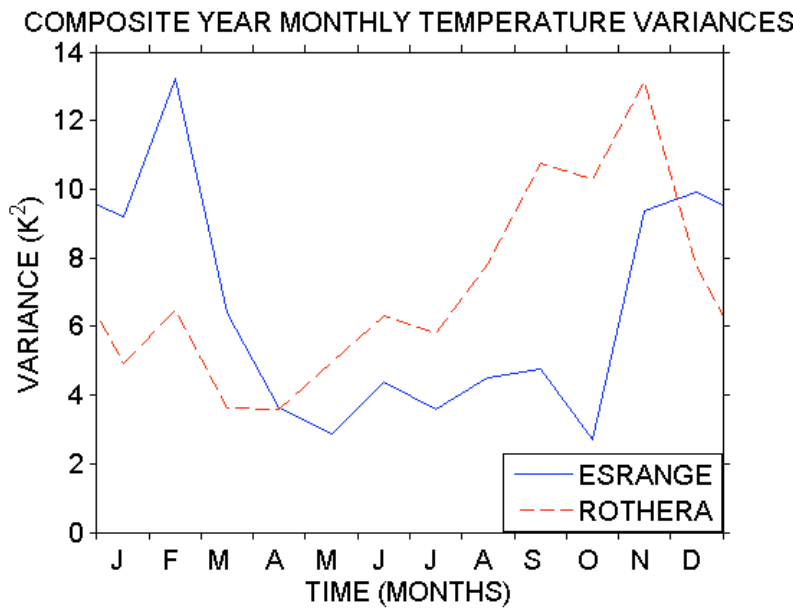

Fig. 9. A composite year analysis of the 16-day wave activity using temperatures over Esrange in the Arctic and Rothera in the Antarctic for the years 2002 to 2009 .

Further investigation into the seasonal variability of the 16-day wave can be made by a composite-year variance analysis of the temperatures, as per the results of Figs. 5 and 6. The results of this analysis are shown in Fig. 9, which presents a composite-year analysis of the temperature variances calculated using all the years data available. From the figure it can be seen that the winter-time wave over Esrange is large from November through to February, reaching variances as large as $\sim 13 \mathrm{~K}^{2}$. The summer-time wave is significantly weaker and the variances only reach $\sim 4 \mathrm{~K}^{2}$. In contrast, the winter-time maximum is not evident over Rothera and, in fact, the largest variances occur in November. From inspection of Fig. $7 \mathrm{~b}$ it can be seen that this spring-time peak largely results from the single large-amplitude event of November 2006.

\section{Discussion}

There are a comparatively small number of published studies of the 16-day wave in the polar MLT. Radar and satellite observations have revealed wave amplitudes of up to about $15 \mathrm{~m} \mathrm{~s}^{-1}$ and $5 \mathrm{~K}$. The wave has been observed to have a wide range of periods ranging from about 12 to 20 days. These observations have been interpreted as a manifestation of the Rossby $(1,3)$ normal mode, proposed on theoretical grounds to have wave periods in the range of 11.1 to 20.0 days by Salby (1981b).

The results presented in Sect. 3 display a clear seasonal behaviour in the occurrence of the 16-day wave in the polar MLT. The wave is evident mainly in the winter over the whole height range observed, but is also present more weakly in the summer-time. The zonal wind component is generally slightly greater than the meridional. 
Williams and Avery (1992) reported observations of the 16-day wave in one year of MST radar data from Poker Flat $\left(65^{\circ} \mathrm{N}\right)$. They reported wave amplitudes maximizing in summer with monthly-mean values of $\sim 6 \mathrm{~m} \mathrm{~s}^{-1}$, roughly comparable to the summer-time amplitudes observed over Esrange and Rothera. Wave activity had equinoctial minima and a weaker secondary maximum in winter. This is different from the multiple-mean year seasonal behaviour reported here. However, the difference may well arise from the fact that they observed only one year and the degree of interannual variability is high. Williams and Avery reported wave periods ranging from 13 to 19 days, which again is very similar to our observations.

Espy et al. (1997) reported observations of the nightly temperatures at heights of about $87 \mathrm{~km}$ made using a groundbased $\mathrm{OH}$ compact Michelson interferometer at Stockholm $\left(60^{\circ} \mathrm{N}\right)$ in June to August of the summers of 1992-1995. They concluded that the 16-day wave was present in 1992 and 1994, but not in 1993 and 1995. They observed temperature perturbations during wave bursts of $\sim 5 \mathrm{~K}$, which is similar to the observations here. They also suggested that the amplitude was much greater in the polar summer mesosphere during eastward (westerly) phases of the QBO. Similar conclusions were drawn by Hibbins et al. (2009) based on observations of the Antarctic summer-time mesosphere. However, our results do not support the conclusion that there is a simple correspondence between the occurrence of the wave in polar summer and the phase of the QBO.

Mitchell et al. (1999) reported observations of the 16-day wave in the MLT using a meteor radar at Sheffield $\left(53^{\circ} \mathrm{N}\right)$ from January 1990 to August 1994. Largest amplitudes were observed in winter-time, where they reached $\sim 14 \mathrm{~m} \mathrm{~s}^{-1}$, comparable to the results presented here. Significant wave activity was observed in mid-summer where it reached $\sim 7$ to $10 \mathrm{~m} \mathrm{~s}^{-1}$ in June and July.

Luo et al. (2000, 2002a,b) carried out a comprehensive study of the 16-day wave using data from multiple MF radars sited from $70^{\circ} \mathrm{N}$ to $2^{\circ} \mathrm{N}$, High Resolution Doppler Imager (HRDI) data, and the Global Scale Wave Model (GSWM) model. The winter-time wave was present at heights of $60-100 \mathrm{~km}$ and reached amplitudes of up to $20 \mathrm{~m} \mathrm{~s}^{-1}$. The summer-time wave was only present at heights above $85 \mathrm{~km}$ and reached amplitudes of $\sim 5$ to $10 \mathrm{~m} \mathrm{~s}^{-1}$. They observed the zonal wave amplitudes to be slightly larger than the meridional. They observed that the summer-time wave was excluded from the regions of strongest westward zonal wind. They found the 16-day wave to be strongest at latitudes of $40^{\circ}$ to $60^{\circ}$ in both hemispheres. Seasonal and inter-annual variability was investigated with the GSWM and, in part, attributed to the Biennial Oscillation (BO) and the Quasi Biennial Oscillation (QBO). They measured the vertical wavelength to be $\sim 50 \mathrm{~km}$ at a height of $85 \mathrm{~km}$ and $30-60 \mathrm{~km}$ across the whole MLT. They attributed the observation of the 16-day wave in the summer-time MLT to cross-equator propagation.
Jiang et al. (2005) observed the MLT with a meteor radar at Wuhan $\left(31^{\circ} \mathrm{N}\right)$ and MF radar at Adelaide $\left(35^{\circ} \mathrm{S}\right)$ during the intervals February 2002 to November 2003 and January 2002 to October 2003, respectively. They reported the seasonal cycle of the 16-day wave. Maximum amplitudes occurred from September to October over Wuhan and July to October over Adelaide. Zonal wave amplitudes were found to be slightly greater than the meridional, as reported here.

Lima et al. (2006) used a meteor radar at Cachoeira Paulista $\left(23^{\circ} \mathrm{S}\right)$ to measure the 16-day wave from April 1999 to April 2004. No clear seasonal behaviour was apparent, although wave activity was observed in summer. They measured peak amplitudes to be $\sim 14 \mathrm{~m} \mathrm{~s}^{-1}$ at a height of $90 \mathrm{~km}$ and measured the vertical wavelength to be $\sim 51 \pm 11 \mathrm{~km}$.

Forbes et al. (1995) reported on both observations and modelling of the 16-day wave in the Northern Hemisphere winter-time MLT. The observations were from a meteor radar at Obninsk $\left(54^{\circ} \mathrm{N}\right)$ a MF radar at Saskatoon $\left(52^{\circ} \mathrm{N}\right)$. They observed wave amplitudes of $\sim 10 \mathrm{~m} \mathrm{~s}^{-1}$ (slightly smaller than the means reported here). Their observations agreed with their modelling study, which predicted wave amplitudes of 5 to $10 \mathrm{~m} \mathrm{~s}^{-1}$. They also modelled temperature amplitudes. At high latitudes they predicted temperature amplitudes of 5 to $10 \mathrm{~K}$, which agrees well with our observations.

The high-latitude results we have presented in Sect. 3 generally agree with those discussed above for middle- and highlatitude studies. We observe similar seasonal cycles in wind, temperature amplitudes to those described. The general pattern of wave activity appears to quite similar in our Arctic and Antarctic observations. There is little evidence of significant differences in the wave between the hemispheres in strong contrast to the inter-hemispheric differences known to be the case for the 2-day wave (e.g., Wu et al., 1993, 1995), although the high level of inter-annual variability prevents us from making definite conclusions.

There are, however, a number of differences between the observations reported here and those of the earlier studies. These differences can probably be attributed to the high degree of inter-annual variability of the 16-day wave. For example, the small winter amplitudes reported by Forbes et al. (1995) and Williams and Avery (1992) may result from interannual variability since similar amplitudes are observed in some of the years of data reported here. The lack of clear seasonal cycle in the study of Lima et al. (2006) almost certainly is because of the low latitude of that study.

The propagation of the 16-day wave into the MLT is controlled by the mean zonal winds, as discussed in Sect. 3 . Charney and Drazin's theorem (1961) explains the free propagation of the 16-day wave from the lower atmosphere to the MLT in winter, as observed. In fact, the observed phase slope in the winter MLT corresponds to an upwardly-propagating wave. However, the zonal wind must have a speed greater than $-10.9 \mathrm{~m} \mathrm{~s}^{-1}$ at $68^{\circ} \mathrm{N} / 68^{\circ} \mathrm{S}$ for the wave to propagate upwards. Therefore, the wave cannot have propagated from 
below in summer-time because of the strong westward winds of the middle atmosphere.

Our observation show that the 16-day wave is largely absent from the regions of strong westward flow observed in summer (e.g. Figs. 5 and 6) this therefore leads to the conclusion that the wave has not propagated from below to the heights where it is observed. As discussed in Sect. 1, it has been proposed that the summer-time wave activity must then result from either ducting across the equator from the winter hemisphere or from in situ excitation by modulated gravitywave fluxes.

If ducting is indeed occurring from the winter to the summer hemisphere, then simultaneous wave activity should be observed in the Arctic and Antarctic. Considering the years of simultaneous data, occurrences of simultaneous wave activity can be searched for. The level of wave activity that we will consider to be significant is taken to be monthly variances of above an arbitrary threshold of $50 \mathrm{~m}^{2} \mathrm{~s}^{-2}$.

Using this criterion, Arctic winter-time wave activity accompanied by simultaneous Antarctic summer-time wave activity can be seen in the Januaries of 2007, 2008, and 2009. Similarly, Antarctic winter-time wave activity accompanied simultaneously by Arctic summer-time wave activity can be seen in September 2005 and October 2006. These episodes are consistent with the possibility of inter-hemispheric ducting, but are not in themselves conclusive proof.

In contrast, there are also episodes of wave activity in the winter-time which are not accompanied by simultaneous summer-time wave activity in the other hemisphere. In particular, Arctic winter-time wave activity is not accompanied by simultaneous Antarctic summer-time wave activity in January 2006. Similarly, Antarctic winter-time wave activity not accompanied by simultaneous Arctic summer-time wave activity in the Septembers of 2007 and 2008. These results suggest that ducting is not occurring in the high latitudes over Esrange and Rothera for at least some years and that therefore if ducting does occur, it does not occur every year. One possible explanation for variability in inter-hemispheric ducting has been proposed by Espy et al. (1997) and Hibbins et al. (2009), who suggests that the QBO strongly modulates such ducting, resulting in a QBO modulation of polar planetary-wave activity in summer.

A deeper investigation of the role of inter-hemispheric ducting would ideally require observations of the 16-day wave at low latitudes where the wave could be observed in any cross-equator duct. Such observations could be made by low-latitude ground-based radars and/or by satellite observations. Observations of a summer-time polar 16-day wave where no such wave was detected crossing the equator would strongly support the proposal that the wave was excited in situ by modulated gravity-wave momentum fluxes (e.g., Williams and Avery, 1992), whereas the presence of such a wave at the equator would support the suggestion of inter-hemispheric ducting (e.g., Miyahara et al., 1991b;
Forbes et al., 1995). We intend to investigate this possibility in a follow-on study.

\section{Conclusions}

The 16-day wave has been observed in both the Arctic and Antarctic MLT using wind and temperature data. The observations span several years and reveal a high level of interannual variability. Observations nevertheless demonstrate that the wave has a clear and well-defined seasonal cycle, which is very similar in each polar region. Throughout the winter the wave is present in all the heights observed $(\sim 80$ $100 \mathrm{~km})$. Wave activity, measured by the winds, during the winter-time was found to be strongest at a height of $\sim 85 \mathrm{~km}$ where it reached amplitudes in excess of $\sim 15 \mathrm{~m} \mathrm{~s}^{-1}$. A summer-time wave was also observed, but with weaker amplitudes seldom in excess of $\sim 6 \mathrm{~m} \mathrm{~s}^{-1}$. Weak wave activity is also evident throughout some of the equinoxes. In all seasons the wave amplitudes vary over time scales of a few tens of days. In the long-term average the wave amplitudes are slightly larger in the zonal component.

The temperature data also reveal a clear 16-day wave signature. Temperature amplitudes typical range from 1 to $6 \mathrm{~K}$. Examination of wind and temperature amplitudes suggests a relationship of form $T^{\prime}=0.27 u^{\prime}$.

Comparisons with other studies reveal generally similar seasonal behaviour, but some differences are apparent. However the high level of inter-annual variability evident in our extended data set suggests that such differences can be explained by the shorter duration of other studies.

In some cases simultaneous wave activity is evident in the winter and summer hemispheres. This observation is not inconsistent with the suggestion that the 16-day wave observed in the summer MLT has propagated there from the winter hemisphere.

Edited by: F.-J. Lübken

\section{References}

Beard, A. G., Mitchell, N. J., Williams, P. J. S., Jones, W., and Muller, H. G.: Mesopause-region tidal variability observed by meteor radar, Adv. Space Res., 20, 1237-1240, 1997.

Charney, J. G. and Drazin, P. G.: Propagation of planetary-scale disturbances from lower into the upper atmosphere, J. Geophys. Res., 66, 83-109, 1961.

Day, K. A. and Mitchell, N. J.: The five-day wave in the arctic and antarctic mesosphere and lower thermosphere, J. Geophys. Res., 115, D091109, doi:10.1029/2009JD012545, 2010.

Dickinson, R. E.: Planetary Rossby waves propagating vertically through weak westerly wind wave guides, J. Atmos. Sci., 25, 984-1002, 1968.

Espy, P. J. and Witt, G.: Observation of a quasi 16-day oscillation in the polar summer mesospheric temperature, Geophys. Res. Lett., 23, 1071-1074, 1996. 
Espy, P. J., Stegman, J., and Witt, G.: Interannual variations of the quasi-16-day oscillation in the polar summer mesospheric temperature, J. Geophys. Res., 102, 1983-1990, 1997.

Forbes, J. M., Jun, G., and Miyahara, S.: On the interactions between gravity waves and the diurnal propagating tides, Planet. Space Sci., 39, 1249-1257, 1991.

Forbes, J. M., Hagan, M. E., Miyahara, S., Vial, F., Mason, A. H., Meek, C. E., and Portnyagin, Y. I.: Quasi 16-day oscillation in the mesosphere and lower thermosphere, J. Geophys. Res., 100, 9149-9163, 1995.

Hibbins, R. E., Jarvis, J. M., and Ford, E. A. K.: Quasi-biennial oscillation influence on long-period planetary waves in the Antarctic upper mesosphere, J. Geophys. Res., 114, D09109, doi:10.1029/2008JD011174, 2009.

Hocking, W., Singer, W., Bremer, J., Mitchell, N. J., Batista, P., Clemesha, B., and Donner, M.: Meteor Radar Temperatures at multiple sites derived with SKiYMET radars and compared to $\mathrm{OH}$, rocket and lidar measurements, J. Atmos. Solar-Terr. Phys., 66, 585-593, 2004.

Hocking, W. K.: Temperatures using radar-meteor decay times, Geophys. Res. Lett., 26, 3229-3300, 1999.

Hocking, W. K., Kelley, M., Roger, R., Brown, W. O. J., Moorcroft, D., and St Maurice, J. P.: Resolute Bay VHF radar: A multipurpose tool for studies of tropospheric motions, middle atmosphere dynamics meteor physics and ionospheric physics, Radio Sci., 36, 1839-1857, 2001.

Jiang, G.-Y., Xiong, J.-G., Wan, W.-X., Ning, B.-Q., Liu, L.-B., Vincent, R. A., and I., R.: The 16-day waves in the mesosphere and lower thermosphere over Wuhan $\left(30.6^{\circ} \mathrm{N}, 114.5^{\circ} \mathrm{E}\right)$ and Adelaide ( $35^{\circ} \mathrm{S}, 138^{\circ}$ E), Adv. Space Res., 35, 2005-2010, 2005.

Kumar, P. and Foufoula-Georgiou, E.: Wavelet analysis for geophysical applications, Rev. Geophys., 35, 385-412, 1997.

Lastovicka, J., Sauli, P., and Krizan, P.: Persistance of planetary wave type oscillations in the mid-latitude ionosphere., Ann. Geophys., 49, 1189-1200, 2006.

Lima, L. M., Batista, P. P., Clemasha, B. R., and Takahashi, H.: 16day wave observed in the meteor winds at low latitudes in the southern hemisphere, Adv. Space Res., 38, 2615-2620, 2006.

Luo, Y., Manson, A. H., Meek, C. E., Meyer, C. K., and Forbes, J. M.: The quasi 16-day oscillation in the mesosphere and lower thermosphere at Saskatoon $\left(52^{\circ} \mathrm{N}, 107^{\circ} \mathrm{W}\right), 1980-1996$, J. Geophys. Res., 195, 2125-2138, 2000.

Luo, Y., Manson, A. H., Meek, C. E., Thayaparan, T., MacDougall, J., and Hocking, W. K.: The 16-day wave in the mesosphere and the lower thermosphere: simultaneous observations at Saskatoon $\left(52^{\circ} \mathrm{N}, 107^{\circ} \mathrm{W}\right)$, London $\left(43^{\circ} \mathrm{N}, 81^{\circ} \mathrm{W}\right)$, Canada, J. Atmos. Solar-Terr. Phys., 64, 1287-1307, 2002a.

Luo, Y., Manson, A. H., Meek, C. E., Meyer, C. K., Burrage, M. D., Fritts, D. C., Hall, C. M., Hocking, W. K., MacDougall, J., Riggin, D. M., and Vincent, R. A.: The 16-day planetary waves: multi-MF radar observations from the arctic to equator and comparisons with the HRDI measurements and the GSWM modelling results, Ann. Geophys., 20, 691-709, 2002b, http://www.ann-geophys.net/20/691/2002/.

Manson, A. H., Meek, C. E., and Hall, G. E.: Correlation of gravity waves and tides in the mesosphere over Sasktoon, J. Atmos. Solar-Terr. Phys., 60, 1089-1107, 1998.

Manson, A. H., Meek, C. E., Luo, Y., Hocking, W. K., MacDougall,
J., Riggin, D., Fritts, D. C., and Vincent, R. A.: Modulation of gravity waves by planetary waves ( 2 and $16 \mathrm{~d}$ ): observations with the North American-Pacific MLT - MFR radar network, J. Atmos. Solar- Terr. Phys., 65, 85-104, 2003.

Merkel, A. W., Thomas, G. E., Palo, S. E., and Bailey, S. M.: Observations of the 5-day planetary wave in PMC measurements from the Student Nitric Oxide Explorer Satellite, Geophys. Res. Lett., 30(4), 1196, doi:10.1029/2002GL016524, 2003.

Merkel, A. W., Garcia, R. R., Bailey, S. M., and Russell III, J. M.: Observational studies of planetary waves in PMCs and mesospheric temperature measured by SNOE and SABER, J. Geophys. Res., 113, D14202, doi:10.1029/2007JD009396, 2008.

Mitchell, N. J., Middleton, H. R., Beard, A. G., Williams, P. J. S., and Muller, H. G.: The 16-day planetary wave in the mesosphere and lower thermosphere, Ann. Geophys., 17, 1447-1456, 1999, http://www.ann-geophys.net/17/1447/1999/.

Mitchell, N. J., Pancheva, D., Middleton, H. R., and Hagan, M. E.: Mean winds and tides in the Artic mesosphere and lower thermosphere, J. Geophys. Res.-Space Phys., 107, A11004, doi:10.1029/2001JA900127, 2002.

Miyahara, S. and Forbes, M.: Interactions between gravity waves and the diurnal tide in the mesosphere and lower thermosphere, J. Meteorol. Soc. Jpn., 69, 523-531, 1991a.

Miyahara, S. P. Y. I., Forbes, J. M., and Solovjeva, T. V.: Mean zonal acceleration and heating of the $70-$ to $100-\mathrm{km}$ region, J. Geophys. Res., 96, 1225-1238, 1991 b.

Miyoshi, Y.: Numerical simulations of the 5-day and 16-day waves in the mesopause region, Earth Planets Space, 51, 763-772, 1999.

Nakamura, T., Fritts, D. C., Isler, J. R., Tsuda, T., Vincent, R. A., and Reid, M.: Short-period fluctuations of the diurnal tide observed with low-latitude MF and meteor radars during CADRE: Evidence for gravity wave/tidal interactions, J. Geophys. Res.Atmos., 102, 26225-26238, 1997.

Pancheva, D. and Mukhtarov, P.: Wavelet analysis on transient behaviour of tidal amplitude fluctuations observed by meteor radar in the lower thermosphere above Bulgaria, Ann. Geophys., 18, 316-331, 2000, http://www.ann-geophys.net/18/316/2000/.

Salby, M. L.: Rossby Normal Modes in Nonuniform Background Configurations. Part I: Simple fields, J. Atmos. Sci., 38, 18031826, 1981a.

Salby, M. L.: Rossby Normal Modes in Nonuniform Background Configurations. Part II: Equinox and Solstice Conditions, J. Atmos. Sci., 38, 1827-1840, 1981b.

Smith, A. K.: The origins of stationary planetary waves in the upper mesosphere, American Meteorological Society, pp. 3033-3041, 2003.

Teitelbaum, H. and Vial, F.: On tidal variability induced by nonlinear interaction with planetary waves, J. Geophys. Res., 96, 14169-14178, 1991.

Thayaparan, T., Hocking, W. H., and MacDougall, J.: Observational evidence of tidal/gravity wave interactions using the UWO 2 MHz radar, Geophys. Res. Lett., 22, 373-376, 1995.

Tunbridge, V. M. and Mitchell, N. J.: The two-day wave in the Antarctic and Arctic mesosphere and lower thermosphere, Atmos. Chem. Phys., 9, 6377-6388, 2009, http://www.atmos-chem-phys.net/9/6377/2009/.

Williams, C. R. and Avery, S. K.: Analysis of long-period waves us- 
ing the mesosphere-stratosphere-troposphere radar at poker flats, Alaska, J. Geophys. Res., 97, 20855-20861, 1992.

Wu, D. L., Hays, P. B., Marshall, A. R., Burrage, M. D., Lieberman, R. S., and Ortland, D. A.: Observations of the quasi 2-day wave from the high resolution doppler imager on UARS, Geophys. Res. Lett., 20, 2853-2856, 1993.
Wu, D. L., Fishbein, E. F., Read, W. G., and Waters, J. W.: Excitation and Evolution of the quasi-2-day wave observed in UARS/MLS temperature measurements, J. Atmos. Sci., 53, 728738, 1995. 